\title{
Extreme Wind Estimates by the Conditional Mean Exceedance Procedure
}

\section{J.L. Gross \\ E. Simiu}

Building and Fire Research Laboratory

\section{N.A. Heckert}

J.A. Lechner

Computing and Applied Mathematics Laboratory

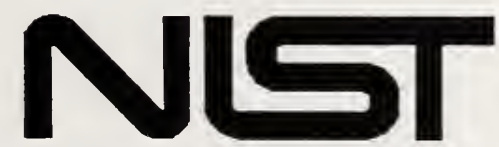

United States Department of Commerce Igy Administration

QC Institute of Standards and Technology

100

.056

*10.5531 



\section{Extreme Wind Estimates by the Conditional Mean Exceedance Procedure}

J.L. Gross, N.A. Heckert, J.A. Lechner and E. Simiu

April 1995

Building and Fire Research Laboratory

National Institute of Standards and Technology

Gaithersburg, MD 20899

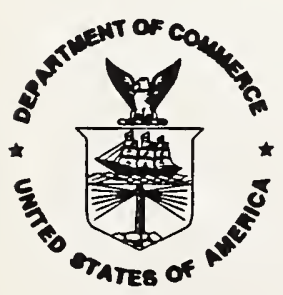

U.S. Department of Commerce

Ronald H. Brown, Secretary

Technology Administration

Mary L. Good, Under Secretary for Technology

National Institute of Standards and Technology

Arati Prabhakar, Director 



\begin{abstract}
We describe work aimed at improving procedures for the estimation of non-tornadic extreme wind speeds, regardless of their direction, in regions not subjected to hurricanes. Using the Generalized Pareto Distribution (GPD) approach and the Conditional Mean Exceedance (CME) estimation method, we analyze 115 17-year to 52-year sets of largest annual speeds and sets drawn from 48 15-year to 26-year records of maximum daily wind speeds. Based on this analysis we attempt an assessment of the widely held belief that the Gumbel distribution with site-dependent location and scale parameters is a universal model of extreme wind speeds. Some of our results suggest that the reverse Weibull distribution is a more appropriate model. This would result in more reasonable estimates of wind-induced failure probabilities and wind load factors than the corresponding estimates based on the Gumbel distribution. However, our assessment is so far only tentative owing to uncertainties inherent in our results. Future work based on lower thresholds (larger data samples) and alternative estimation methods is planned.
\end{abstract}




\section{INTRODUCTION}

Until recently methods for the estimation of extreme wind speeds were based solely on classical extreme value theory (Gumbel, 1958). Although such methods can be used to obtain credible estimates of wind speeds with relatively short mean return periods (50 years, say), questions remain as to their capability to estimate distribution tails reliably.

In the last two decades a novel theory known as the "peaks over threshold" approach was developed that offers the potential for more realistic estimates of the tails. This would allow the estimation by statistical methods of wind load factors, which have to date been specified in building standards on the basis of engineering guesses passed from one generation of standards to the next. This paper is part of a long-term project aimed at improving estimates of wind speed distribution tails and wind load factors. The "peaks over threshold" approach rests on the application of the Generalized Pareto Distribution (GPD) to the excess of the extreme variates over a fixed threshold. For terminology and notations, see Gross et al. (1994).

Unlike classical methods, the "peaks over threshold" approach is applicable to the analysis of the set consisting of all data exceeding a sufficiently high threshold. In addition, it is applicable to data taken from sets of epochal extremes (i.e., maxima over samples of fixed size, such as largest annual wind speeds). According to classical theory, in the asymptotic limit a set of epochal extremes must fit the tail of one of the three extreme value distributions. The epochal extremes that exceed a sufficiently high threshold must therefore fit the GPD with $c>0$, $c \rightarrow 0$, or $c<0$.

We review briefly in Section 2 the expression for the GPD, the GPD-based estimator used in this work, and the estimation within the framework of the "peaks over threshold" approach of variates with specified mean return periods. In Section 3 we analyze 115 sets of observed largest annual wind speeds taken from 17- to 52-year records. Section 4 is devoted to analyses of sets taken from 48 15- to 26-year records of largest daily speeds. Section 5 presents our conclusions and outlines future work.

\section{GENERALIZED PARETO DISTRIBUTION, AND DESCRIPTION OF ESTIMATORS}

We review here the expression for the Generalized Pareto Distribution and the Conditional Mean Exceedance (CME) method for estimating distribution parameters.

\section{Generalized Pareto Distribution (GPD)}

The expression for the GPD is

$$
\mathrm{G}(\mathrm{y})=\operatorname{Prob}[\mathrm{Y} \leq \mathrm{y}]=1-\left\{[1+(\mathrm{cy} / \mathrm{a})]^{-1 / c}\right\} \quad \mathrm{a}>0,(1+(\mathrm{cy} / \mathrm{a}))>0
$$

Equation 1 can be used to represent the conditional cumulative distribution of the excess $\mathrm{Y}=\mathrm{V}$ - $\mathrm{u}$ of the variate $\mathrm{V}$ over the threshold $\mathrm{u}$, given $\mathrm{V}>\mathrm{u}$ for $\mathrm{u}$ sufficiently large; $\mathrm{c}$ and a are distribution parameters. The cases $c>0, c=0$ and $c<0$ correspond, respectively, to Fréchet, Gumbel, and reverse Weibull (right tail-limited) domains of attraction. For $c=0$ the expression between braces is understood in a limiting sense as the exponential exp $(-y / a)(C a s t i l l o, ~ 1988, p$. 215). For $c<0$ the shape parameter of the corresponding distribution is $\gamma=-1 / c$ (Smith, 1989). 


\section{Cumulative Mean Exceedance (CME) Method}

The CME is the expectation of the amount by which a value exceeds a threshold $u$, conditional on that threshold being attained. If the exceedance data are fitted by the GPD model and $c<1, u>0$, and $a+u c>0$, then the CME vs. u plot should follow a line with intercept a/(1c) and slope $c /(1-c)$ (Davison et al., 1990). The linearity of the plot is an indicator of the appropriateness of the GPD model. Estimates of $\mathrm{c}$ and a can be obtained from the slope and intercept of a straight line fit to the CME vs. $u$ plot.

\section{Estimation of variates with specified mean return periods}

The mean return period $R$, in years, of a given wind speed is defined as the inverse of the probability that that wind speed will be exceeded in any one year. In this section we give expressions that allow the estimation from the GPD of the value of the variate corresponding to probability $1-1 /(\lambda R)$, where $\lambda$ is the mean crossing rate of the threshold u per year (i.e., the average number of data points above the threshold u per year), and $R$ is the mean recurrence interval in years. We have

$$
\begin{aligned}
& \operatorname{Prob}\left(Y<y_{R}\right)=1-1 /(\lambda R) \\
& 1-\left[1+c y_{R} / a\right]^{-1 / c}=1-1 /(\lambda R) \\
& y_{R}=-a\left[1-(\lambda R)^{c}\right] / c \\
& V_{R}=y_{R}+u
\end{aligned}
$$

where $V_{R}$ is the $R$-year wind speed (e.g., $V_{50}=50$-year speed) and $u$ is the threshold used to estimate $c$ and a. For epochal sets consisting of the largest annual wind speeds, $\lambda=1$. Note that, given $u, \lambda, c, R$ and $V_{R}$, Eqs. 4 and 5 yield the parameter a inherent in the estimation of $V_{R}$.

\section{ANALYSIS OF LARGEST ANNUAL WIND SPEEDS}

Table A1 given in Appendix A shows estimated values of the tail length parameter, $\hat{c}$. The estimates were obtained by applying the CME method to data samples taken from $115 \mathrm{~N}$ year records of observed largest annual wind speeds adjusted to a $10 \mathrm{~m}$ elevation above ground $(17<N<52)$. Stations where strong winds are predominantly due to hurricanes were not included in Table A1. All wind speeds are given by the Weather Service in terms of fastest miles. For this report, wind speeds have been converted to SI units $(1 \mathrm{mph}=0.44704 \mathrm{~m} / \mathrm{s})$. In order to include only the strongest winds in each set -- the winds most likely to approach the asymptotic condition inherent in the GPD approach -- we used the CME estimator based for each record on a relatively high threshold. We chose this threshold to be equal to the record's median wind speed, $\mathrm{V}_{\text {med }}$. All the CME-based results of Table A1 are based on this threshold. In our calculations for observed data a wind speed, $V$, was defined as exceeding the threshold if $\mathrm{V} \geq \mathrm{V}_{\text {med }}$, that is, the actual threshold is actually smaller (by an infinitesimal amount) than the nominal threshold. 
For the threshold $V_{\text {mod }}$, the sample average number of exceedances was $E\left(n_{e x}\right)=21$, and $\mathrm{E}\left(\mathrm{V}_{\mathrm{mos}}\right)=50, \mathrm{SD}\left(\mathrm{V}_{\text {mes }}\right)=6.5$ ( $\mathrm{E}$ and $\mathrm{SD}$ denote sample mean and standard deviation). The mean and standard deviation of the estimated values of $\mathrm{c}$ listed in Table A1 are:

$$
\mathrm{E}(\hat{\mathrm{c}})=-0.26, \mathrm{SD}(\hat{\mathrm{c}})=0.38 \text {. }
$$

We denote by $V_{\text {mod. }}$ and $V_{\text {mod }}$ the speed preceding $V_{\text {med }}$ and the speed following $V_{\text {med }}$, respectively, in the set of ordered speeds of which $V_{\text {med }}$ is the median. Using a threshold $V_{\text {med- }}$, $\mathrm{E}\left(\mathrm{n}_{\mathrm{ex}}\right)=24$ and a threshold $\mathrm{V}_{\mathrm{med}+}, \mathrm{E}\left(\mathrm{n}_{\mathrm{ex}}\right)=17$, results not listed in Table A1 yielded

$$
\begin{aligned}
& \mathrm{E}(\hat{\mathrm{c}})=-0.24, \mathrm{SD}(\hat{\mathrm{c}})=0.34 \\
& \mathrm{E}(\hat{\mathrm{c}})=-0.27, \mathrm{SD}(\hat{\mathrm{c}})=0.48,
\end{aligned}
$$

respectively. For lower thresholds $\mathrm{E}(\hat{\mathrm{c}})$ was found to increase.

The following results were obtained from Monte Carlo simulations. For 500 25-year samples with mean exceedance rate $\lambda=1$ and $\hat{c}$ estimated by the CME method,

$\mathrm{E}(\hat{\mathrm{c}})=-0.09, \mathrm{SD}(\hat{\mathrm{c}})=0.27$ (population with Gumbel distribution)

$\mathrm{E}(\hat{\mathrm{c}})=-0.33, \mathrm{SD}(\hat{\mathrm{c}})=0.24$ (population with reverse Weibull distr., $\gamma=-1 / \mathrm{c}=1 / 0.275$ ).

A comparison between the results based on the observed data on the one hand and on the simulated data on the other would suggest that a reverse Weibull distribution with shape parameter $\gamma \approx 5(c=-0.2)$ is a more appropriate model than the Gumbel distribution. (The Gumbel distribution can be interpreted as the limit of a family of three-parameter extreme value distributions as the shape parameter approaches infinity -- see proof in Simiu et al., 1986)

Let us now hypothesize, nevertheless, that the Gumbel distribution is an appropriate universal model of extreme wind speeds, that is, that for every station the true tail length parameter is $\mathrm{c}=0$. The results of the Monte Carlo simulations just shown indicate a bias of about -0.1 in the estimation of $\mathrm{c}$, so let us allow for a bias as large as -0.1 in estimating c. Using a binomial distribution model (with mean $\mathrm{n} / 2=57.5$ and standard deviation $(\mathrm{n})^{1 / 2} / 2=5.36$ ), one would expect that about half of the 115 estimated values of $c$ would be below -0.1 . Actually, 77 estimated values (significantly more than half) are below -0.1 ; this number is almost four standard deviations higher than the mean, and would lead to a rejection of the hypothesis that the Gumbel distribution is a universal model for the extreme speeds. However, this tentative conclusion may not be warranted. Indeed, each station may have a different true $c$, and the sample sizes for the various stations differ. Instead of the average $\mathrm{E}(\hat{\mathrm{c}})$ for the observed data, it would therefore be appropriate to consider a weighted average of $c$, where each weight is equal to the inverse of the variance of the estimate of $c$. Standard deviations of these estimates are listed in Table A1 and were obtained by the expression

$$
\operatorname{SD}(\hat{\mathrm{c}})=\frac{[\Sigma(\mathrm{n}-\mathrm{i})]^{1 / 2}\left[\Sigma(\mathrm{n}-\mathrm{i})\left(\mathrm{y}_{\mathrm{i}}-\text { intercept }-\mathrm{x}_{\mathrm{i}} \cdot(\text { slope })\right)^{2}\right]^{1 / 2}}{(\mathrm{n}-3)^{1 / 2}(1+\text { slope })^{2} \cdot\left\{[\Sigma(\mathrm{n}-\mathrm{i})]\left[\Sigma(\mathrm{n}-\mathrm{i}) \mathrm{x}_{\mathrm{i}}^{2}\right]-\left[\Sigma(\mathrm{n}-\mathrm{i}) \mathrm{x}_{\mathrm{i}}\right]^{2}\right\}^{1 / 2}}
$$

where $n$ is the number of data in the set, $x_{i}$ are the speeds $(i=1,2, \ldots, n-1)$, and $y_{i}$ are CME values (see Appendix B). The weighted mean of the c estimates, based on these standard deviations, is close to -0.1 , and its standard deviation is about $0: 32$. Note that the simplifying assumption implicit in Eq. 6 that the errors in the estimation of $y_{i}$ for various i's are independent is not correct, and the standard deviations of the c estimates are actually larger than those given by Eq. 6 by factors that pilot Monte Carlo simulations suggested can be as high as two or even more. We conclude that owing to the small sample sizes we used, we do not get a sufficiently good estimate of the weighted average of $\hat{c}$, and the inference made earlier on the basis of the binomial distribution cannot be relied upon with confidence. 
A comparison between the tabulated values of CME-based estimated $V_{N}$ 's and values of the maximum speeds on record, $V_{\max }$, shows that the performance of the CME estimator of $V_{N}$ is very good. We note, however, that a worse set of $V_{N}$ estimates was obtained, where the CME method was applied to data samples in which identical speeds were made distinct by addition of multiples of 0.001 . Though the estimates of $\mathrm{c}$ were not much affected by this change, this sensitivity of the CME method appears to cast some shadow upon its dependability.

The CME estimates of $V_{100000}$ appear to be worse than those of $V_{N}$ : in some cases they differ minimally from the estimates of $\mathrm{V}_{\mathrm{N}}$; in others they can be ridiculously large. We also show in Table A1 wind speed estimates based on the Gumbel model. These were obtained by the probability plot correlation coefficient method (PPCC). It is seen that estimates of $V_{N}$ based on the Gumbel model are comparable to those based on the CME method.

Table A1 also lists CME-based estimated speeds with mean return period 100000 years, $\hat{\mathrm{V}}_{100000}$, where the parameter $\mathrm{a}$ is based on the CME-based estimated value of $\mathrm{V}_{\mathrm{N}}$, as indicated in the remark following Eqs. 4 and 5, and on a specified $c=-0.2$.

\section{Load Factors}

Let $R_{u}$ denote the mean return period of the ultimate load. If the wind load predominates (i.e., no load combination need be considered), the wind load factor is

$\phi=\left(\mathrm{V}_{\mathrm{Ru}} / \mathrm{V}_{50}\right)^{2}$

Table A1 lists estimated values of $\phi$ based on Eq. 7, where $V_{50}$ was based on the CME estimates of $V_{N}$, and $V_{R u}$, corresponding to asymptotically large $R_{u}$, was based on a parameter a estimated from $V_{N}$ by using Eqs. 4 and 5, and the specified parameter $c=-0.2$ Depending upon the site, the estimates of $\phi$ vary between 1.24 and 1.68. Their average is $\phi=1.42$, as compared to $\phi=1.3$ specified in the ASCE Standard 7-93 and earlier versions thereof.

\section{Structural Reliability Implications}

Consider, for example, the Fresno, CA data set. Under the assumption that the Gumbel distribution best fits the extremes, for $R_{u}=10^{3}$ years, $10^{5}$ and $10^{6}$ years, the estimated wind speeds are 26, 34 and $38 \mathrm{~m} / \mathrm{s}(59,77$ and $86 \mathrm{mph}$ ), respectively (Simiu et al., 1979). Under the assumption that the reverse Weibull with $\gamma=-1 / \mathrm{c}=1 / 0.20$ holds, they are 24,26 and $27 \mathrm{~m} / \mathrm{s}(54$, 59 , and $60 \mathrm{mph}$ ), respectively. It is seen that the tail is considerably shorter for the reverse Weibull than for the Gumbel.

Failure probabilities for wind-sensitive structures designed in accordance with U.S. building code requirements (or safety indices reflecting those probabilities) have been estimated on the basis of the Gumbel model. Ellingwood et al. (1980) found such estimates to be substantially higher than for other types of structures. Experience shows that the number of structural failures caused by non-tornadic and non-hurricane winds is vastly smaller than those estimates would indicate. One possible flaw of those probability estimates is in our opinion the fact that they are based on the Gumbel distribution which, as suggested by our results, overestimates extreme winds corresponding to long mean return periods.

The result that the upper tail of the extreme wind speed distribution is finite would invalidate the notion that probabilities of failure of a structure subjected only to wind loading, conditional on the structural strength being sufficiently large, are always larger than zero: if the 
structural strength corresponded to a wind speed larger than the length of the finite distribution tail, then the conditional failure probability would be zero.

\section{ANALYSES OF DATA BASED ON SETS OF LARGEST DAILY WIND SPEEDS}

In this section we first analyze data sets that reflect not only extreme winds occurring at various sites, but also ordinary winds. The analyses are intended to verify whether such sets can provide information on the parent population of the extremes. Next, we use a GPD-based approach to analyze sets of data that exceed relatively high thresholds.

\section{Data Selection}

From sets of largest daily wind speeds we obtained data samples that: (1) are relatively large so that sampling errors are acceptably small, and (2) have reduced mutual dependence among the data. The procedure for obtaining the data is as follows: Partition the set of daily maxima into small periods of size equal to or larger than the duration of typical storms in days. (A reasonable choice of the length of the period is eight days, but we also use sets based on four-day periods, and compare results of analyses based on the two choices.) Pick the largest value in each period. If the maxima of two adjacent periods are less than half a period apart, replace the smaller of the two maxima by the next smaller value in the respective period which is at least half a period apart from the larger maximum. A data set is thus obtained in which adjacent data are one period apart on the average and never less than half a period apart. We show below the daily maxima at Boise, Idaho in the first six eight-day periods of the year 1965. The periods are separated by vertical bars. The data selected by the procedure just described are in bold type. In the sixth period we underlined the period maximum (26), discarded and replaced by the next largest value (18) because of the proximity to the larger maximum (31) of the adjacent period.

$$
\begin{aligned}
& 23,32,35,20,26,24,24,14|13,16,5,11,5,12,12,7| 6,6,9,9,11,12,25,26 \mid \\
& 15,12,12,7,15,12,29,10|7,10,15,20,20,17,24,31| \underline{26,9,16,14,18,16,14,12} \mid
\end{aligned}
$$

Our investigation attempts to ascertain whether sets of data selected by this procedure from a set of daily maxima could possibly constitute samples from the parent populations of the extremes. Even though small correlations among data might subsist, we refer to a set obtained by the selection procedure just described as an uncorrelated data set based on eight-day (fourday) intervals or, for short, an eight-day (four-day) interval set.

\section{Analysis of Uncorrelated Data Sets}

We considered 48 uncorrelated data sets based on eight-day intervals, with length $\mathrm{N}$ ranging from 15 to 26 years. First we analyzed separately the sets of spring, summer, fall and winter data (seasonal data analyses). Next, we analyzed the data sets unsegregated by seasons. In both cases we estimated the best-fitting distributions (i.e., distributions with the largest PPCC) from among a set of seven distributions or families of distributions (normal, double exponential, lognormal, Gumbel, Fréchet, Weibull, and reverse Weibull). 
Our goal in performing the seasonal analyses was to attempt to fit to the spring, summer, fall and winter data, respectively, cumulative distributions $P_{s p}(v), P_{s}(v), P_{f}(v)$ and $P_{w}(v)$. Given these distributions, the distribution for all the uncorrelated data is

$P(v)=P_{s p}(v) P_{s}(v) P_{f}(v) P_{w}(v)$.

We analyzed, for each season, 48 sets based on eight-day intervals. According to our results, for the spring, fall and winter records the best fitting distribution was predominantly reverse Weibull with shape $4 \leq \gamma \leq 30$. However, 29 summer records were better fitted by Gumbel distributions than by the reverse Weibull; the reverse Weibull (for the stations where it fitted the data better than the Gumbel distribution), and the Gumbel distribution (for the other stations), yielded estimated speeds with mean return period $N$ years, $V_{N}$, that in most cases underpredicted the maximum speed recorded during $\mathrm{N}$ years, $\mathrm{V}_{\max , \mathrm{N}}$. For summer records underpredictions were 15 percent or more for 16 sets, and 8 to 15 percent for 9 sets; there were only two overpredictions, both less than 8 percent. For spring records there were 12 underpredictions by 8 to 18 percent, and only three overpredictions, all less than 5 percent; comparable results were obtained for fall and winter. The results did not depend significantly on whether eight-day interval sets or four-day interval sets were used. From these and additional analyses we concluded that: (1) inferences from seasonal data sets (obtained as was described earlier from samples of largest daily data) do not provide a dependable basis for estimating extremes, but are likely to underestimate the extreme speeds. In other words, those sets are not drawn from populations underlying the extreme winds, but from mixed populations; (2) a similar conclusion applies to the sets consisting of all largest daily data for each season; (3) for these reasons the approach embodied in Eq. 8 appears to be inapplicable if all the data of the 8-day interval sets are considered.

Some researchers have indicated that the Weibull (as opposed to reverse Weibull) distribution best fits the sets of largest daily data. However, our analysis showed that the Weibull distribution fitted the seasonal data best only for less than ten percent of the sets.

\section{Data sets unsegregated by seasons}

The analysis of 48 sets based on eight-day intervals showed that the reverse Weibull (with $4 \leq \gamma \leq 22$ ) was the best fitting distribution for 27 sets, and fitted the data better than the Gumbel distribution for 41 sets. For 25 sets out of these 41 sets, including 12 sets for which it was optimal, the reverse Weibull underpredicted $V_{\max , \mathrm{N}}$ by 8 to 25 percent. For the 48 sets there were only 4 overpredictions, all smaller than 5 percent. In addition, the availability of largest annual data for periods $N_{1}$ ranging from 30 to 49 years allowed us to check the predictive capability of models inferred from sets based on eight-day intervals by comparing the estimated speed with mean return period $\mathrm{N}_{1}, \mathrm{~V}_{\mathrm{N} 1}$, to the maximum speed recorded during an $\mathrm{N}_{1}$-year period, $\mathrm{V}_{\max , \mathrm{N} 1}$, where $30 \leq N_{1} \leq 49$. The underpredictions of the $N_{1}$-year speeds were more frequent and drastic than those of the $\mathrm{N}$-year speeds. We concluded that estimated distributions of data sets unsegregated by seasons are too affected by the bulk of the non-extreme data to yield satisfactory estimates of extremes. Each of our conclusions for data segregated by seasons were found to be valid for data unsegregated by seasons as well. 


\section{Numerical Experiments}

The analyses reported in the preceding paragraph showed that even where other distributions best fitted the data, the reverse Weibull was in most cases very close to being the best fitting distribution, i.e., its PPCC differed only in the fourth or even fifth significant figure from the PPCC of the best fitting distribution. We therefore reanalyzed the data based on eightday intervals by assuming that the populations for all stations have a single reverse Weibull distribution with site-dependent location and scale parameters. This was done by calculating, for each station, the PPCC's based on the assumption that the shape parameter $\gamma$ is $1,2,3, \ldots 50$. For samples of data based on eight-day intervals and unsegregated by seasons the mean value of the PPCC's, taken over all the stations, was largest for $\gamma=11$, and the median PPCC was largest for $\gamma=13$. This is an indication that a reverse Weibull population with $\gamma=12$ would explain the results of the analyses. To see whether this is in fact the case, 48 samples of 730 data points each (corresponding to an 18-year record length based on 8-day intervals) were generated from reverse Weibull populations with (1) $\gamma=8$, (2) $\gamma=12$, and (3) $\gamma=16$. The number of simulated sets for which the best fitting reverse Weibull distribution had shape parameters with $\gamma \leq 12$, $13 \leq \gamma \leq 20$, and $\gamma \geq 21$ are shown in Table 1. Also shown in Table 1 are the numbers of observed sets (average sample size 18 years) with $\gamma \leq 12,13 \leq \gamma \leq 20$, and $\gamma \geq 21$. The results of Table 1 suggest that a reverse Weibull distribution with $\gamma \approx 12$ is an appropriate model for the population of extreme winds representing data based on 8-day intervals unsegregated by seasons, except for the larger number of samples with $\gamma \geq 21$ among the observed samples than among the simulated samples. We interpret this larger number as reflecting the relatively frequent presence of outliers among the observed samples. In our opinion this interpretation reinforces the point made earlier that, because wind speed populations which include ordinary speeds in addition to extremes are mixed, samples taken from such populations are not a sound basis for inferences on extremes. It is therefore necessary to "let the tails speak for themselves." This is done by applying to the data the GPD-based "peaks over threshold" approach.

Table 1. Numbers of Sets Best Fitted by Distributions with Various Values of $\boldsymbol{\gamma}$

$$
\gamma \leq 12 \quad 13 \leq \gamma \leq 20 \quad \gamma \geq 21
$$

\begin{tabular}{lrrr}
\hline Simulated sets, $\gamma=8$ & 48 & 0 & 0 \\
Simulated sets, $\gamma=12$ & 27 & 17 & 4 \\
Simulated sets, $\gamma=16$ & 8 & 24 & 16 \\
Observed sets & 26 & 12 & 10
\end{tabular}

\section{"Peaks over Threshold" Analyses}

In carrying out "peaks over threshold" analyses it is tempting to use a relatively low threshold in order to increase the number of data and thus reduce sampling errors. However, this introduces in the samples data that are not representative of the extremes and tend to bias the results. So that this does not happen the threshold being selected should be as high as possible, without reducing the size of the sample being analyzed to the point where the sampling errors become too large. 
We selected the largest possible threshold subject to the restriction that the resulting sample size of the exceedances not be smaller than 15. Based on this selection, the average number of exceedances for our 48 sets based on 8-day intervals was $E\left(n_{e x}\right)=16$, and the average threshold was $\mathrm{E}\left(\mathrm{V}_{\mathrm{T}}\right)=45$, that is, less than the average median, $\mathrm{E}(\mathrm{M})=50$, for the largest yearly speed samples analyzed in Section 3. For these thresholds we obtained $E(\hat{c})=-0.22$ and $\operatorname{SD}(\hat{\mathrm{c}})=0.44$. The results were virtually the same for the 48 sets based on 4-day intervals. These results would appear to lend support to the tentative conclusion of Section 3 that the extreme winds are described by a reverse Weibull distribution with shape parameter $\gamma \approx 5$, or perhaps somewhat larger, rather than by a Gumbel distribution. However, the weighted mean of the estimated c's, obtained as was shown for the results of Table A1, was close to zero. In addition, there were about as many estimated c's larger than -0.1 as there were smaller than -0.1 . These results would suggest that the Gumbel distribution is appropriate. However, given the very wide confidence bands for our results, we conclude that no statement on whether the Gumbel or the reverse Weibull distribution is more appropriate can be made on the basis of this analysis.

In principle, the approach inherent in Eq. 8 may be based on "peaks over threshold" analyses. However, given that the records at our disposal are relatively short and the number of data exceeding a sufficiently high threshold for each of the seasons was judged to be too small, no attempt to perform "peaks over threshold" seasonal analyses was made in this work.

\section{CONCLUSIONS}

It is currently assumed in engineering loading models that non-hurricane and non-tornadic extreme wind speeds, regardless of their direction, are described by the Gumbel distribution (which corresponds to a shape parameter $\gamma=-1 / \mathrm{c}$ approaching infinity). The Gumbel distribution has infinite upper tail. The objective of this paper was to gain insights into the question of whether extreme wind speeds can be described by an extreme value distribution with limited upper tail, that is, by the reverse Weibull distribution.

We used in our analyses observed data, consisting of (a) sets of largest annual wind speeds, and (b) sets of largest daily wind speeds from which we extracted subsets suitable for extreme value analysis; and simulated data. Our results appear to suggest that extreme winds are better described by the reverse Weibull distribution than by the Gumbel distribution. However, given the small sample sizes used in our analyses, the superiority of one of the distributions over the other cannot be affirmed with confidence.

The tentative assumption that the extreme wind distributions are reverse Weibull, with shape parameter $\gamma \approx 5$ (GPD tail length parameter $c=-0.2$ ) and site-dependent location and scale parameters, yields wind load factors with an average value $\phi \approx 1.4$. This assumption, if confirmed, would invalidate earlier approaches to the estimation of the reliability of windsensitive structures, which depend on an infinite-tailed model of extreme wind speeds and therefore yield unrealistically high failure probabilities.

The "peaks over threshold" analyses were based in this paper on the Cumulative Mean Exceedance (CME) approach, which appears to be extremely sensitive to whether identical values of the variate in a set are left identical or modified by the addition to each of a different number much smaller than unity. Future work aimed at verifying the tentative conclusions of this paper will therefore include analyses based on different estimation procedures, including the de Haan procedure (Dekkers et al., 1989). In addition, we plan to perform analyses based on larger data sets, and more elaborate Monte Carlo simulations, in which the sets of samples 
generated by simulation will have the same sizes as the observed data sets being analyzed, rather than having a constant size. Finally, investigations are envisaged into the possibility that the shape parameter of the extreme wind speed distributions is site-dependent. This would be a departure from current practice, in which it is assumed that extreme winds are described by an extreme value distribution with universal shape parameter (that is, by the Gumbel distribution, which corresponds to a GPD tail length parameter $c \approx 0$ ), and site-dependent location and scale parameters.

\section{ACKNOWLEDGMENTS}

We thank S. Coles, D. Walshaw and P. Bortot for valuable suggestions and comments.

\section{REFERENCES}

ASCE Standard A7-93 (1994), Minimum Design Loads for Buildings and Other Structures, American Society of Civil Engineers, New York.

Castillo, E. (1988), Extreme Value Theory in Engineering, Academic Press, New York.

Davison, A.C., and Smith, R.L. (1990), "Models of Exceedances Over High Thresholds," Journal of the Royal Statistical Society, Series B, Vol. 52, pp. 339-442.

Dekkers, A.L.M., Einmahl, J.H.J., and de Haan, L. (1989b), "A Moment Estimator for the Index of an Extreme-value Distribution," Annals of Statistics, Vol. 17, pp. 1833-1855.

Draper, N. R. and Smith, H. (1966), Applied Regression Analysis, John Wiley \& Sons, New York, pp. 77-80.

Ellingwood, B. R. et al., (1980), Development of a probability-based load criterion for Amer. National Standard A58, NBS Special Publ. 577, Natl. Bureau of Standards, Washington, D.C.

Gross, J. L., Heckert, A.N., Lechner, J.A., and Simiu, E. (1994), "Novel Extreme Value Estimation Procedures: Application to Extreme Wind Data, " Proc., International Conference on Extreme Value Theory and Its Applications, J. Galambos et al. (eds.), Kluwer , Boston.

Gumbel, E. (1958), Statistics of Extremes, Columbia University Press, New York.

Pickands, J.(1975), "Statistical Inference Using Order Statistics," Annals Stat., Vol.3, 119-131.

Simiu, E., Changery, M. J. and Filliben, J.J.(1979), Extreme Wind Speeds at 129 Stations in the Contiguous United States, NBS BSS 118, Natl. Bureau of Standards, Washington, D.C.

Simiu, E., \& Scanlan, R.H.(1986), Wind Effects on Structures, Wiley-Interscience, New York. 
Smith, R. L. (1989), Extreme Value Theory, in Handbook of Applicable Mathematics, Supplement (W. Ledermann et al., editors), pp. 437-472, John Wiley and Sons, New York. 
Table A1. Results of Analyses of Sets of Largest Annual Data

\begin{tabular}{|c|c|c|c|c|c|c|c|c|c|c|c|c|c|c|}
\hline & $\begin{array}{l}\text { Station } \\
\text { (1) }\end{array}$ & $\begin{array}{l}\mathbf{N} \\
\text { (2) }\end{array}$ & $\begin{array}{l}V_{\text {max }} \\
\text { (3) }\end{array}$ & $\begin{array}{l}V_{\text {med }} \\
\text { (4) }\end{array}$ & $\begin{array}{l}\mathrm{n}_{\mathrm{e}} \\
\text { (5) }\end{array}$ & & $\begin{array}{r}\operatorname{SD}(\mathbf{c}) \\
(7)\end{array}$ & $\begin{array}{r}v \\
\text { um. }\end{array}$ & (9) & $\begin{array}{r}\mathbf{V}_{\text {so }} \mid \\
\mathbf{C M E} \\
(10)\end{array}$ & $\begin{array}{r}\text { CME } \\
(11)\end{array}$ & $\begin{array}{l}V_{100000} \\
\text { Gum. } \\
(12)\end{array}$ & $\begin{aligned}= & -.20 \\
& (13)\end{aligned}$ & $\begin{array}{c}\phi \\
(14)\end{array}$ \\
\hline 1. & BIRMINGHAM, AL & 34 & 62 & 44 & 22 & -0.495 & 0.084 & 64 & 62 & 65 & 69 & 104 & 81 & 1.47 \\
\hline 2. & MONTGOMERY, AL & 34 & 77 & 45 & 17 & 0.442 & 0.022 & 66 & 65 & 72 & 1071 & 117 & 95 & 1.56 \\
\hline 3. & TUCSON, AZ & 39 & 78 & 50 & 21 & 0.187 & 0.086 & 76 & 71 & 79 & 273 & 121 & 103 & 1.54 \\
\hline 4. & YUMA, AZ & 39 & 65 & 46 & 20 & -0.701 & 0.056 & 65 & 66 & 66 & 68 & 116 & 83 & 1.44 \\
\hline 5. & FORT SMITH, AR & 31 & 64 & 45 & 17 & -0.798 & 0.158 & 63 & 64 & 64 & 65 & 113 & 80 & 1.43 \\
\hline 6. & LITTLE ROCK, AR & 39 & 72 & 44 & 21 & -0.395 & 0.070 & 72 & 71 & 73 & 83 & 136 & 97 & 1.59 \\
\hline 7. & FRESNO, CA & 37 & 47 & 34 & 21 & -0.204 & 0.036 & 47 & 46 & 48 & 59 & 77 & 59 & 1.42 \\
\hline 8. & RED BLUFF, CA & 42 & 67 & 49 & 25 & -0.751 & 0.115 & 67 & 69 & 67 & 68 & 114 & 81 & 1.38 \\
\hline 9. & SACRAMENTO, CA & 39 & 63 & 43 & 20 & -0.668 & 0.106 & 62 & 64 & 62 & 65 & 114 & 78 & 1.45 \\
\hline 10. & SAN DIEGO, CA & 48 & 61 & 35 & 27 & 0.384 & 0.022 & 56 & 50 & 57 & 584 & 85 & 75 & 1.57 \\
\hline 11. & DENVER, CO & 33 & 61 & 48 & 17 & -0.265 & 0.112 & 60 & 61 & 61 & 69 & 93 & 72 & 1.30 \\
\hline 12. & GRAND JUNCTION, CO & 33 & 70 & 52 & 17 & 0.104 & 0.065 & 67 & 66 & 70 & 146 & 103 & 86 & 1.37 \\
\hline 13. & PUEBLO, CO & 43 & 79 & 61 & 25 & -0.477 & 0.060 & 80 & 81 & 80 & 85 & 126 & 95 & 1.34 \\
\hline 14. & HARTFORD, CT & 44 & 67 & 43 & 28 & -0.238 & 0.028 & 67 & 64 & 68 & 84 & 109 & 87 & 1.54 \\
\hline 15. & WASHINGTON, DC & 39 & 66 & 47 & 24 & -0.325 & 0.055 & 67 & 65 & 68 & 77 & 106 & 84 & 1.44 \\
\hline 16. & ATLANTA, GA & 42 & 76 & 46 & 22 & -0.034 & 0.030 & 74 & 72 & 76 & 134 & 131 & 101 & 1.59 \\
\hline 17. & MACON, GA & 33 & 64 & 45 & 17 & -0.271 & 0.073 & 64 & 65 & 66 & 79 & 118 & 84 & 1.46 \\
\hline 18. & BOISE, ID & 48 & 62 & 47 & 24 & -0.099 & 0.068 & 62 & 61 & 62 & 84 & 92 & 75 & 1.35 \\
\hline 19. & POCATELLO, ID & 48 & 72 & 53 & 25 & 0.019 & 0.157 & 75 & 71 & 75 & 132 & 113 & 94 & 1.43 \\
\hline 20. & CHICAGO MIDWAY, IL & 37 & 63 & 46 & 22 & -0.128 & 0.028 & 63 & 61 & 64 & 86 & 97 & 79 & 1.41 \\
\hline 21. & MOLINE, IL & 44 & 72 & 52 & 25 & -0.665 & 0.082 & 72 & 75 & 73 & 75 & 124 & 90 & 1.41 \\
\hline 22. & PEORIA, IL & 42 & 72 & 50 & 22 & -0.302 & 0.075 & 70 & 72 & 71 & 82 & 122 & 89 & 1.43 \\
\hline 23. & SPRINGFIELD, IL & 32 & 71 & 54 & 16 & -0.199 & 0.118 & 68 & 69 & 69 & 83 & 110 & 83 & 1.32 \\
\hline 24. & EVANSVILLE, IN & 44 & 61 & 47 & 23 & -0.130 & 0.106 & 63 & 63 & 63 & 82 & 103 & 77 & 1.36 \\
\hline 25. & FORT WAYNE, IN & 46 & 69 & 52 & 23 & -0.163 & 0.063 & 69 & 70 & 70 & 88 & 110 & 85 & 1.37 \\
\hline 26. & INDIANAPOLIS, IN & 36 & 93 & 53 & 18 & 0.023 & 0.064 & 81 & 81 & 85 & 171 & 151 & 113 & 1.56 \\
\hline 27. & BURLINGTON, IA & 23 & 72 & 55 & 13 & -1.751 & 0.515 & 69 & 76 & 69 & 69 & 140 & 80 & 1.28 \\
\hline 28. & DES MOINES, IA & 37 & 80 & 56 & 19 & 0.042 & 0.034 & 79 & 77 & 81 & 155 & 133 & 102 & 1.45 \\
\hline 29. & SIOUX CITY, IA & 46 & 88 & 57 & 24 & 0.063 & 0.065 & 85 & 80 & 85 & 180 & 132 & 110 & 1.49 \\
\hline 30. & CONCORDIA, KS & 20 & 74 & 56 & 11 & -0.933 & 0.188 & 73 & 76 & 74 & 75 & 145 & 89 & 1.35 \\
\hline 31. & DODGE CITY, KS & 41 & 72 & 59 & 22 & -0.709 & 0.048 & 72 & 75 & 72 & 73 & 114 & 83 & 1.25 \\
\hline 32. & TOPEKA, KS & 34 & 79 & 54 & 17 & -0.180 & 0.160 & 71 & 74 & 73 & 91 & 128 & 90 & 1.38 \\
\hline 33. & WICHITA, KS & 41 & 89 & 57 & 22 & 0.218 & 0.056 & 83 & 80 & 86 & 325 & 134 & 110 & 1.49 \\
\hline 34. & LOUISVILLE, KY & 39 & 66 & 49 & 21 & -0.085 & 0.055 & 63 & 65 & 64 & 87 & 107 & 77 & 1.34 \\
\hline 35. & PORTLAND, ME & 45 & 73 & 46 & 23 & -0.283 & 0.088 & 73 & 70 & 73 & 90 & 122 & 97 & 1.55 \\
\hline 36. & BALTIMORE, MD & 39 & 71 & 54 & 20 & -0.274 & 0.078 & 70 & 71 & 71 & 81 & 116 & 85 & 1.34 \\
\hline 37. & BOSTON, MA & 50 & 85 & 54 & 26 & -0.126 & 0.039 & 84 & 81 & 84 & 119 & 139 & 109 & 1.52 \\
\hline 38. & NANTUCKET, MA & 23 & 71 & 55 & 14 & -1.402 & 0.217 & 71 & 73 & 72 & 72 & 128 & 85 & 1.33 \\
\hline 39. & DETROIT, MI & 46 & 68 & 49 & 25 & -0.207 & 0.091 & 67 & 68 & 67 & 81 & 111 & 82 & 1.38 \\
\hline 40. & GRAND RAPIDS, MI & 29 & 67 & 47 & 15 & -0.930 & 0.128 & 69 & 71 & 70 & 71 & 136 & 89 & 1.47 \\
\hline 41. & LANSING, MI & 38 & 67 & 51 & 21 & -0.646 & 0.063 & 68 & 69 & 68 & 71 & 110 & 83 & 1.36 \\
\hline 42. & SAULT STE MARIE, MI & 47 & 67 & 46 & 24 & -0.351 & 0.059 & 65 & 67 & 65 & 74 & 113 & 82 & 1.43 \\
\hline 43. & DULUTH, MN & 36 & 70 & 49 & 19 & -0.310 & 0.033 & 69 & 70 & 70 & 81 & 122 & 88 & 1.44 \\
\hline 44. & MINNEAPOLIS, MN & 42 & 82 & 46 & 27 & -0.023 & 0.048 & 79 & 72 & 81 & 149 & 127 & 108 & 1.65 \\
\hline 45. & JACKSON, MS & 29 & 64 & 44 & 16 & -0.353 & 0.073 & 64 & 62 & 66 & 75 & 109 & 84 & 1.48 \\
\hline & $\begin{array}{l}\text { COLUMBIA, MO } \\
\text { KANSAS CITY, MO }\end{array}$ & $\begin{array}{l}35 \\
51\end{array}$ & $\begin{array}{l}65 \\
75\end{array}$ & $\begin{array}{l}51 \\
49\end{array}$ & $\begin{array}{l}20 \\
31\end{array}$ & $\begin{array}{l}-0.103 \\
-0.116\end{array}$ & $\begin{array}{l}0.075 \\
0.038\end{array}$ & $\begin{array}{l}66 \\
74\end{array}$ & $\begin{array}{l}66 \\
72\end{array}$ & $\begin{array}{l}67 \\
74\end{array}$ & $\begin{array}{r}89 \\
104\end{array}$ & $\begin{array}{l}109 \\
120\end{array}$ & $\begin{array}{l}81 \\
94\end{array}$ & $\begin{array}{l}1.35 \\
1.49\end{array}$ \\
\hline 48. & ST.LOUIS, MO & 21 & 66 & 46 & 14 & 0.035 & 0.075 & 64 & 62 & 70 & 135 & 111 & 89 & 1.51 \\
\hline
\end{tabular}




\begin{tabular}{|c|c|c|c|c|c|c|c|c|c|c|c|c|c|c|}
\hline & & & & & & & & $\mathbf{V}_{N}$ & 1 & $\mathbf{v}_{\mathbf{s o}_{0}} \mathbf{I}$ & & $V_{100000}$ & 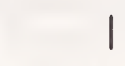 & \\
\hline & Station & $\mathbf{N}$ & $V_{\text {max }}$ & $V_{\text {med }}$ & $\mathrm{n}_{\mathrm{a}}$ & c & $\operatorname{SD}(\hat{c})$ & Gum.C & ME & & CME & Gum. c & & $\phi$ \\
\hline & (1) & (2) & (3) & (4) & (5) & (6) & (7) & (8) & (9) & (10) & (11) & (12) & (13) & (14) \\
\hline 49. & SPRINGFIELD, MO & 44 & 71 & 49 & 22 & -0.127 & 0.068 & 68 & 67 & 69 & 93 & 111 & 86 & 1.42 \\
\hline 50. & BILLINGS, MT & 49 & 84 & 58 & 26 & -0.051 & 0.031 & 84 & 81 & 84 & 130 & 132 & 106 & 1.45 \\
\hline 51. & GREAT FALLS, MT & 44 & 75 & 59 & 24 & -0.400 & 0.078 & 74 & 78 & 74 & 80 & 125 & 87 & 1.29 \\
\hline 52. & HAVRE, MT & 27 & 78 & 57 & 14 & -0.229 & 0.227 & 77 & 76 & 80 & 97 & 135 & 99 & 1.41 \\
\hline 53. & HELENA, MT & 48 & 71 & 55 & 25 & -0.241 & 0.114 & 70 & 71 & 70 & 81 & 111 & 83 & 1.31 \\
\hline 54. & MISSOULA, MT & 43 & 71 & 47 & 22 & -0.157 & 0.050 & 71 & 65 & 72 & 97 & 105 & 92 & 1.50 \\
\hline 55. & NORTH PLATTE, NE & 31 & 74 & 61 & 16 & -0.709 & 0.044 & 74 & 77 & 75 & 76 & 123 & 87 & 1.26 \\
\hline 56. & OMAHA, NE & 51 & 104 & 50 & 29 & 0.294 & 0.054 & 92 & 81 & 91 & 640 & 145 & 125 & 1.68 \\
\hline 57. & VALENTINE, NE & 27 & 74 & 61 & 15 & -0.574 & 0.120 & 74 & 78 & 76 & 78 & 130 & 88 & 1.27 \\
\hline 58. & ELY, NV & 49 & 70 & 51 & 28 & -0.191 & 0.023 & 70 & 68 & 70 & 87 & 107 & 86 & 1.39 \\
\hline 59. & LAS VEGAS, NV & 20 & 70 & 55 & 12 & -0.938 & 0.362 & 68 & 70 & 69 & 69 & 121 & 80 & 1.28 \\
\hline 60. & RENO, NV & 45 & 77 & 55 & 24 & -0.463 & 0.053 & 77 & 78 & 77 & 83 & 129 & 96 & 1.41 \\
\hline 61. & WINNEMUCCA, NV & 38 & 63 & 47 & 21 & -1.102 & 0.071 & 63 & 67 & 64 & 64 & 114 & 77 & 1.37 \\
\hline 62. & CONCORD, NH & 46 & 68 & 41 & 23 & -0.040 & 0.038 & 66 & 63 & 66 & 116 & 111 & 89 & 1.58 \\
\hline 63. & ALBUQUERQUE, NM & 52 & 85 & 56 & 26 & 0.139 & 0.023 & 79 & 78 & 78 & 195 & 124 & 98 & 1.41 \\
\hline 64. & ROSWELL, NM & 36 & 82 & 57 & 18 & 0.088 & 0.119 & 81 & 81 & 84 & 190 & 145 & 108 & 1.48 \\
\hline 65. & ALBANY, NY & 46 & 68 & 46 & 29 & -0.086 & 0.081 & 66 & 64 & 67 & 95 & 103 & 83 & 1.45 \\
\hline 66. & BINGHAMPTON, NY & 35 & 65 & 48 & 18 & -0.370 & 0.081 & 64 & 66 & 65 & 72 & 115 & 80 & 1.38 \\
\hline 67. & BUFFALO, NY & 44 & 79 & 52 & 22 & 0.463 & 0.050 & 73 & 69 & 74 & 1049 & 109 & 94 & 1.45 \\
\hline 68. & LA GUARDIA, NY & 33 & 73 & 57 & 17 & 0.314 & 0.032 & 71 & 71 & 74 & 344 & 113 & 89 & 1.33 \\
\hline 69. & ROCHESTER, NY & 45 & 66 & 52 & 23 & -0.717 & 0.094 & 66 & 69 & 66 & 67 & 106 & 78 & 1.30 \\
\hline 70. & SYRACUSE, NY & 45 & 67 & 51 & 23 & 0.014 & 0.089 & 66 & 65 & 66 & 105 & 100 & 79 & 1.33 \\
\hline 71. & CHARLOTTE, NC & 29 & 65 & 42 & 17 & -0.481 & 0.244 & 65 & 62 & 67 & 73 & 112 & 87 & 1.55 \\
\hline 72. & GREENSBORO, NC & 50 & 67 & 41 & 25 & -0.089 & 0.073 & 62 & 62 & 62 & 94 & 109 & 81 & 1.51 \\
\hline 73. & BISMARCK, ND & 40 & 69 & 58 & 20 & -0.582 & 0.145 & 69 & 72 & 69 & 71 & 107 & 79 & 1.23 \\
\hline 74. & FARGO, ND & 45 & 100 & 57 & 25 & 0.252 & 0.032 & 93 & 86 & 95 & 484 & 151 & 127 & 1.60 \\
\hline 75. & WILLISTON, ND & 18 & 69 & 56 & 9 & -0.469 & 0.127 . & 68 & 68 & 71 & 75 & 116 & 84 & 1.31 \\
\hline 76. & CLEVELAND, OH & 35 & 69 & 53 & 19 & -0.224 & 0.080 & 68 & 69 & 69 & 81 & 111 & 82 & 1.33 \\
\hline 77. & COLUMBUS, OH & 30 & 61 & 49 & 15 & -1.236 & 0.106 & 60 & 64 & 60 & 60 & 106 & 70 & 1.26 \\
\hline 78. & DAYTON, OH & 41 & 72 & 52 & 24 & -0.170 & 0.072 & 74 & 72 & 75 & 97 & 121 & 94 & 1.45 \\
\hline 79. & TOLEDO, OH & 45 & 82 & 48 & 24 & 0.207 & 0.050 & 76 & 72 & 78 & 308 & 125 & 103 & 1.57 \\
\hline 80. & OKLAHOMA CITY, OK & 30 & 69 & 53 & 15 & -0.135 & 0.081 & 67 & 67 & 69 & 89 & 105 & 84 & 1.35 \\
\hline 81. & TULSA, OK & 35 & 68 & 49 & 18 & 0.019 & 0.107 & 63 & 65 & 65 & 106 & 109 & 79 & 1.35 \\
\hline 82. & PORTLAND, OR & 38 & 88 & 49 & 19 & 0.268 & 0.077 & 80 & 75 & 85 & 503 & 138 & 116 & 1.64 \\
\hline 83. & HARRISBURG, PA & 38 & 64 & 45 & 19 & -0.599 & 0.087 & 63 & 65 & 64 & 67 & 114 & 80 & 1.42 \\
\hline 84. & PHILADELPHIA, PA & 33 & 62 & 47 & 21 & -0.507 & 0.094 & 63 & 64 & 64 & 67 & 105 & 77 & 1.38 \\
\hline 85. & PITTSBURGH, PA & 18 & 60 & 47 & 11 & -0.591 & 0.132 & 61 & 60 & 63 & 65 & 102 & 75 & 1.36 \\
\hline 86. & SCRANTON, PA & 33 & 57 & 44 & 17 & -0.387 & 0.092 & 56 & 57 & 57 & 62 & 89 & 68 & 1.32 \\
\hline 87. & BLOCK ISLAND, RI & 31 & 86 & 60 & 16 & -0.182 & 0.120 & 82 & 82 & 84 & 107 & 138 & 105 & 1.42 \\
\hline 88. & GREENVILLE, SC & 43 & 72 & 46 & 22 & -0.483 & 0.069 & 69 & 75 & 70 & 76 & 143 & 90 & 1.50 \\
\hline 89. & HURON, SD & 49 & 79 & 59 & 26 & -0.447 & 0.059 & 80 & 82 & 80 & 86 & 132 & 98 & 1.38 \\
\hline 90. & RAPID CITY, SD & 43 & 70 & 62 & 22 & -0.341 & 0.096 & 71 & 73 & 72 & 76 & 102 & 80 & 1.18 \\
\hline 91. & CHATTANOOGA, TN & 35 & 76 & 46 & 18 & -0.336 & 0.066 & 76 & 73 & 78 & 93 & 141 & 105 & 1.61 \\
\hline 92. & KNOXVILLE, TN & 33 & 66 & 50 & 18 & 0.007 & 0.042 & 66 & 65 & 68 & 111 & 109 & 83 & 1.38 \\
\hline 93. & MEMPHIS, TN & 21 & 61 & 45 & 11 & -0.370 & 0.369 & 57 & 58 & 59 & 65 & 103 & 71 & 1.34 \\
\hline 94. & NASHVILLE, TN & 34 & 70 & 45 & 17 & -0.178 & 0.092 & 67 & 66 & 70 & 94 & 119 & 91 & 1.53 \\
\hline 95. & ABILENE, TX & 36 & 100 & 54 & 19 & 0.550 & 0.047 & 79 & 78 & 85 & 2491 & 141 & 111 & 1.54 \\
\hline 96. & AMARILLO, TX & 34 & 81 & 62 & 17 & 0.201 & 0.082 & 77 & 78 & 79 & 214 & 124 & 95 & 1.32 \\
\hline 97. & AUSTIN, TX & 37 & 58 & 45 & 19 & -0.189 & 0.057 & 57 & 58 & 58 & 69 & 91 & 68 & 1.31 \\
\hline 98. & DALLAS, TX & 32 & 67 & 48 & 17 & -0.233 & 0.043 & 65 & 64 & 67 & 81 & 107 & 83 & 1.41 \\
\hline 99. & EL PASO, TX & 32 & 67 & 55 & 17 & -0.187 & 0.103 & 68 & 67 & 69 & 82 & 99 & 81 & 1.28 \\
\hline
\end{tabular}


$\begin{array}{llllll} & V_{N} & \mid V_{s 0} & V_{10000} & \mid\end{array}$

Station $\quad \mathrm{N} \mathrm{V}_{\operatorname{mx}} \mathrm{V}_{\text {med }} \mathrm{n}_{a} \quad \mathrm{C}$ SD(c) Gum.CME CME CME Gum. $c=-.20$

(1)

(2) (3) (4) (5)

(6)

(7)

(8) (9) (10)

(11)

(12)

(13)

(14)

100. SAN ANTONIO, TX

101. SALT LAKE CITY, UT

102. BURLINGTON, VT

103. LYNCHBURG, VA

104. RICHMOND, VA

105. NORTH HEAD, WA

106. QUILLAYUTE, WA

107. SEATTLE, WA

108. SPOKANE, WA

$\begin{array}{rrrrr}36 & 80 & 46 & 19 & 0.236 \\ 46 & 69 & 49 & 28 & -0.333\end{array}$

$\begin{array}{lllll}40 & 66 & 44 & 23 & -0.232\end{array}$

$\begin{array}{lllll}44 & 53 & 39 & 22 & -0.750\end{array}$

$\begin{array}{lllll}33 & 61 & 42 & 20 & 0.192\end{array}$

$\begin{array}{lllll}41 & 104 & 67 & 28 & -0.250\end{array}$

$\begin{array}{llllll}21 & 45 & 35 & 12 & -0.184\end{array}$

$\begin{array}{lllll}20 & 59 & 43 & 11 & 0.027\end{array}$

$\begin{array}{lllll}47 & 65 & 48 & 24 & 0.028\end{array}$

109. TATOOSH ISLAND, WA

110. GREEN BAY, WI

111. MADISON, WI

112. MILWAUKEE, WI

113. CHEYENNE, WY

114. LANDER, WY

115. SHERIDAN, WY

$\begin{array}{llllll}54 & 86 & 66 & 27 & -0.290\end{array}$

$\begin{array}{lllll}36 & 103 & 54 & 18 & 0.431\end{array}$

$\begin{array}{lllll}41 & 75 & 48 & 21 & -0.516\end{array}$

$\begin{array}{lllll}42 & 68 & 54 & 21 & -0.423\end{array}$

$\begin{array}{llllll}46 & 73 & 61 & 24 & -0.476\end{array}$

$\begin{array}{rrrrr}42 & 80 & 58 & 21 & -0.621 \\ 44 & 82 & 61 & 24 & 0.125\end{array}$

0.041

0.038

0.093

0.154

0.058

0.055
0.018

0.069

0.040

0.045

0.089

0.058

0.059

0.051

$\begin{array}{lllllll}70 & 68 & 73 & 328 & 123 & 96 & 1.55\end{array}$

$\begin{array}{rrrrrrr}70 & 69 & 70 & 80 & 113 & 88 & 1.44\end{array}$

$\begin{array}{lllllll}66 & 63 & 67 & 84 & 107 & 86 & 1.51\end{array}$

$\begin{array}{lllllll}52 & 56 & 52 & 53 & 94 & 63 & 1.37\end{array}$

$\begin{array}{lllllll}59 & 56 & 63 & 204 & 95 & 79 & 1.48\end{array}$

$\begin{array}{rlrrrrr}105 & 96 & 106 & 130 & 158 & 136 & 1.55\end{array}$

$\begin{array}{lllllll}45 & 44 & 47 & 58 & 72 & 57 & 1.37\end{array}$

$\begin{array}{lllllll}56 & 56 & 62 & 112 & 97 & 77 & 1.44\end{array}$

$\begin{array}{lllllll}64 & 64 & 65 & 111 & 101 & 79 & 1.37\end{array}$

$\begin{array}{lllllll}86 & 85 & 86 & 98 & 128 & 104 & 1.34\end{array}$

$\begin{array}{lllllll}85 & 82 & 92 & 1408 & 153 & 126 & 1.63\end{array}$

$\begin{array}{lllllll}75 & 75 & 76 & 82 & 134 & 100 & 1.54\end{array}$

$\begin{array}{rrrrrrr}67 & 70 & 67 & 72 & 109 & 79 & 1.29\end{array}$

$\begin{array}{lllllll}74 & 76 & 74 & 77 & 113 & 85 & 1.24\end{array}$

$\begin{array}{lllllll}77 & 83 & 77 & 80 & 142 & 94 & 1.35\end{array}$

\begin{tabular}{|c|c|c|c|}
\hline MEAN & $\begin{array}{llll}38.1 & 71.9 & 50.4 & 20.5\end{array}$ & -0.257 (unweighted) & 1.42 \\
\hline SD & $\begin{array}{llll}8.2 & 10.5 & 6.3 & 4.5\end{array}$ & 0.384 (unweighted) & 0.10 \\
\hline
\end{tabular}

Key:

Col. Notation Description

(1) Station

(2) $\mathrm{N}$

(3) $\mathrm{V}_{\max }$

(4) $V_{\text {mod }}$

(5) $\mathrm{n}_{\mathrm{ex}}$

(6) $\hat{\mathrm{c}}$

(7) $\mathrm{SD}(\hat{c})$

(8) $\mathrm{V}_{\mathrm{N}}$ Gum

(9) $V_{N}$ CME

Name of NWS Station

Sample size

Maximum observed wind speed (mph)

Median observed wind speed ( $\mathrm{mph}$ )

Number of exceedances

Estimated c

Standard deviation of $\hat{\mathbf{c}}$

Estimated N-yr wind based on Gumbel model ( $\hat{c}$ from Col. 6)

(10) $\mathrm{V}_{50} \mathrm{CME}$

Estimated N-yr wind based on CME method ( $\hat{c}$ from Col. 6)

(11) $\mathrm{V}_{100000} \mathrm{CME}$

Estimated 50-yr wind based on CME method ( $\hat{c}$ from Col. 6 )

(12) $V_{100000}$ Gum

Estimated 100,000-yr wind based on CME method ( $\hat{c}$ from Col. 6)

(13) $\mathrm{V}_{100000} \mathrm{c}=-.2$

Estimated 100,000-yr wind based on Gumbel model ( $\hat{c}$ from Col. 6)

(14) $\phi$

Estimated 100,000-yr wind based on CME method $(c=-0.20)$

Load factor based on $c=-0.20$

Note: $1 \mathrm{mph}=0.44704 \mathrm{~m} / \mathrm{s}$ 


\section{APPENDIX B}

\section{Estimation of SD of $\hat{\mathbf{c}}$}

We consider the problem of fitting $\mathrm{CME}_{\mathrm{i}}=$ intercept + slope $\cdot \mathrm{X}_{\mathrm{i}}+\epsilon_{\mathrm{i}}$ where the variance of $\epsilon_{\mathrm{i}}$ is proportional to $1 /(\mathrm{n}-\mathrm{i})$ for $\mathrm{i}=1,2, \ldots, \mathrm{n}-1$.

\section{GIVEN:}

1) Speeds $x_{i}, i=1,2, \ldots, n$

2) $\quad$ ME values $y_{i}, i=1,2, \ldots,(n-1)$

Define "relative variances" $v_{i}=(n-i)^{-1}, i=1,2, \ldots,(n-1)$ and $\underline{V}=\operatorname{diag}(\underline{v})$.

Let $\underline{B}^{\mathrm{T}}=$ [intercept slope $] \underline{\mathrm{x}}^{\mathrm{T}}=\left[\mathrm{x}_{1}, \mathrm{x}_{2}, \ldots, \mathrm{x}_{\mathrm{n}-1}\right]$ and $\underline{\mathrm{X}}=[\underline{\mathrm{x}}]$ (T denotes transpose).

Also, let $\underline{\mathrm{M}}=\left[\underline{\mathrm{X}}^{\mathrm{T}} \mathrm{V}^{-1} \underline{\mathrm{X}}\right]^{-1}$

$$
=\left[\begin{array}{cc}
\sum(n-i) & \sum(n-i) x_{i} \\
\sum(n-i) x_{i} & \sum(n-i) x_{i}^{2}
\end{array}\right]^{-1}=(S S X)^{-1}\left[\begin{array}{cc}
\sum(n-i) x_{i}^{2} & -\sum(n-i) x_{i} \\
-\sum(n-i) x_{i} & \sum(n-i)
\end{array}\right]
$$

(All summations are for $\mathrm{i}=1,2, \ldots,(\mathrm{n}-\mathrm{i})$.)

Here and below, $\operatorname{SSX}=\left[\sum(n-i)\right]\left[\sum(n-i) x_{i}^{2}\right]-\left[\sum(n-i) x_{i}\right]^{2}$.

Then the parameter estimates $\underline{\mathrm{b}}$ are given by:

$$
\underline{b}=\underline{M}\left[\begin{array}{c}
\sum(n-i) y_{i} \\
\sum(n-i) x_{i} y_{i}
\end{array}\right] \text {; }
$$

with covariance matrix $\sigma^{2} \underline{\mathrm{M}}$;

and $\hat{\sigma}^{2}$ is $(1 /(n-i))\left(y-\underline{x}^{T} \underline{b}\right)^{T} \underline{V}^{-1}\left(\underline{y}-\underline{x}^{T} \underline{b}\right)$

$$
=(1 /(n-1)) \sum(n-i)\left(y_{i}-\text { intercept }- \text { slope } \cdot x_{i}\right)^{2} .
$$

Our estimate of $\hat{\mathbf{c}}$ is slope/(1+slope); and the estimated standard deviation of the c-estimate is $(1+\text { slope })^{-2}$ times the standard deviation of the slope, or to within a constant (see Draper and Smith, 1966)

$$
\operatorname{SD}(\hat{\mathrm{c}})=\frac{\left[\sum(\mathrm{n}-\mathrm{i})\right]^{1 / 2}\left[\sum(\mathrm{n}-\mathrm{i})\left(\mathrm{y}_{\mathrm{i}}-\text { intercept }- \text { slope } \cdot \mathrm{x}_{\mathrm{i}}\right)^{2}\right]^{1 / 2}}{(\mathrm{n}-3)^{1 / 2}(1+\text { slope })^{2}(\mathrm{SSX})^{1 / 2}}
$$



